\title{
Entrevista: Professora Debora Diniz
}

\section{Cláudia Türner P. Duarte ${ }^{1}$}

Mestranda em Direito Público pela UERJ.

\section{Cristina Telles ${ }^{2}$}

Mestra em Direito Público pela UERJ.

\section{Debora Diniz}

Professora da Faculdade de Direito da Universidade de Brasília (UnB); Doutora em Antropologia pela Universidade de Brasília (UnB); pesquisadora da ANIS - Instituto de Bioética; Vice-Presidente da International Women's Health Coalition.

1. Você tem dedicado grande parte de seu trabalho a questões que lidam com a temática do gênero, ou, mais concretamente, com a situação das mulheres no Brasil. $\mathrm{O}$ que levou você a escolher esse assunto?

Esta é uma pergunta difícil de ser respondida se eu fizer uso da verdade - como o farei. Qualquer tentativa soará como uma narrativa de mito de origem que, na verdade, nunca existiu. O que posso lhes contar é que jamais pensei a intelectualidade, isto é, o trabalho acadêmico e de pesquisa, desconectado do mundo real e, portanto, do engajamento

1 Promotora de Justiça (MPRJ).

${ }^{2}$ Assessora de Ministro do Supremo Tribunal Federal. Advogada do BNDES licenciada. 
político. Não fui liderança em tempo de escola ou mesmo na universidade; nem mesmo esse socorro bonito para a origem eu poderia ter. Acredito na política sindical, mas nunca fui sindicalista; defendo os partidos, mas não sou filiada a nenhum.

Mas o mundo vivido sempre me importou - talvez por isso tenha perambulado tanto pelas carreiras universitárias antes de me decidir pela antropologia. Não foram convicções íntimas que me fizeram aprender o ofício de antropóloga, mas uma sensibilidade para o vivido. Talvez, seja mais prudente me descrever como etnógrafa do que mesmo como antropóloga. Ao me deparar com o vivido, e não com as abstrações sobre como o mundo deve ser, é que me conectei com as histórias de gente, com os corpos no mundo, com os sofrimentos na história. Talvez, por uma experiência subjetiva no feminino, eu tenha me movido rapidamente para o feminismo e para os estudos de gênero. Mas, como veem, não tenho um mito original e desbravador, mas uma trajetória intelectual; sensível, é verdade, mas muito comum à vida universitária.

Assim, se não houve um evento de origem - o mito fundador do feminismo em minha vida -, houve negociações provocadas pela sensibilidade feminista que me fizeram uma intelectual engajada. Para apresentar-me nos meus próprios termos, gosto mesmo é de descrever-me como "amadora engajada" (Diniz, 2016a). Sou antropóloga pelos títulos, mas sou professora em uma Faculdade de Direito, na Universidade de Brasília, faço pesquisas nas interfaces entre diferentes saberes: da literatura à saúde. Por isso, sou uma amadora em duplo sentido: tenho muita paixão pelo que faço, mas, talvez, não seja uma especialista tal como se espera da formação acadêmica por fronteiras entre campos. Passeio pelo conhecimento, faço conexões entre o litígio estratégico e o cinema documental, adoro pensar questões políticas pela literatura ficcional. Talvez, seja uma profanação essa prática intelectual e argumentativa. Mas me defini (também) como engajada - e é por isso que me perguntam: não escrevo, penso; movo-me ou inquieto-me por temas que não sejam do mundo vivido, e os que tocam diretamente a sobrevivência e os direitos de pessoas em sofrimento ou desvantagem social (Diniz, 2015a). Por isso, ter me aproximado da questão das mulheres e do feminismo foi como um tsunami intelectual: os temas só se renovam - da anencefalia para a epidemia do zika em pouco mais de uma década.

É claro que, no meio desse processo de encontro entre o pensamento e o engajamento, as resistências facilitaram meu enquadramento próprio como feminista engajada: no início de minha carreira fui demitida da Universidade Católica de Brasília, onde era professora. A tese da universidade era contenção de recursos ou algo 
semelhante; a minha sempre foi de perseguição por minhas pesquisas sobre aborto. Fui demitida no mesmo dia em que recebi um prêmio da Organização Pan-Americana de Saúde pelas pesquisas em saúde e direitos reprodutivos. Não gosto de retornar ao passado e dizer o que pensava ou vivia ali, pois sempre são profecias auto-realizadoras, mas posso lhes garantir que, se ali não era já uma feminista laica, fiz desses títulos um monumento de existência.

2. Dentro da temática do gênero, qual ponto você considera mais importante ou com maior potencial transformador no Brasil? Há, em paralelo, algum ponto que você repute mais urgente?

Queria primeiro provocar o sentido de gênero - este termo maldito para as redes sociais ou para algumas igrejas. Fala-se até em ideologia de gênero, uma invenção curiosa para um conceito acadêmico quase inofensivo. Gênero no sentido terrível das redes sociais é uma ideologia de perversão, uma alteração da ordem natural da vida e das coisas. É pecaminoso, uma blasfêmia. Bem, talvez, pronunciar gênero seja sofredor para os que sustentam haver ordem natural na vida - as mulheres são isso ou aquilo porque é a ordem da natureza; o pênis se acopla na vagina porque assim seria a natureza. Aí está o incômodo sobre falar em gênero: não há natureza; há, desde sempre, criação cultural. Até mesmo isso que olhamos ao nosso redor e imaginamos como matéria anterior à cultura é simplesmente criação de discursos. Não há texto natural que espontaneamente se moveria para criar sentidos para a vida moralizada (Diniz, 2015b). Assim, falar em gênero é desnaturalizar o mundo - desiludir-se com a natureza, preciso ser honesta, é um baita sofrimento para aqueles que preferem não pensar. Desnaturalizar o mundo é devolver potência de agência, ou dito mais simplesmente, assumir o poder de escolha para nós humanos, como sujeitos da história. Não é do além-mundo que os sentidos e destinos serão criados. É da vida na história.

Por isso, entendo gênero como uma norma política que nos forma e conforma (Diniz, 2015b): ao nascer, somos sexadas - meninas ou meninos é a retórica binária que nos move. O binarismo sexual se crê soberano pela natureza; essa é a falácia moral que o texto sobre gênero tenta nos provocar, daí seu caráter insuportável. Não é o corpo com esse ou aquele desenho que grita a sexagem como uma identificação, mas é a moral sobre os corpos que classifica a matéria. Sexo e gênero, em certa medida, são o mesmo, já dizia 
Judith Butler (2003): desde sempre uma norma política sobre quem se espera que venhamos a ser desde o nascimento. No entanto, mesmo sexo e gênero sendo o mesmo, como construções discursivas sobre os corpos sexados - há algo de perturbador no conceito de gênero: foi ele que nos gritou não ser a sexagem um destino, agora parodiando Simone de Beauvoir (2009). Por isso, corpos sexados como fêmeas podem se apresentar como transhomens, corpos sexados como machos se apresentam como travestis. É do cerne da ilusão de natureza que abunda a criatividade e a ruptura com expectativas de destino para os corpos.

Foi porque conseguimos desafiar o discurso sobre o natural como um destino que as mulheres puderam escolher se queriam ou com quem queriam ter filhos; que puderam votar; que puderam não se subordinar ao pai, aos irmãos ou aos maridos; que puderam escolher as roupas ou assumir cargos de liderança. Isso tudo é falar em gênero. A confusão do fanatismo atual sobre gênero é resumir gênero às fantasias de práticas sexuais - é novamente o tabu do sexo, o medo do prazer ser conhecido por todos, que faz o escândalo contemporâneo da palavra gênero. Não é curioso esse jogo ambíguo? É preciso repetir - falar em gênero não é imoral nem pecaminoso, é só pensar como vivemos os corpos sexados na vida cotidiana.

Mas vocês ainda me perguntam se haveria agenda prioritária para os estudos de gênero ou para a pauta feminista. Por um retrocesso político e pré-civilizatório da sociedade brasileira, eu diria que é absoluta prioridade falarmos em gênero, em desbancarmos pretensões naturalizantes da vida dos corpos, seja na sexualidade ou em qualquer outra esfera da vida. Mas, em um nível concreto de temas, jamais poderia deixar de mencionar a importância da questão do aborto - é um tema que toca diretamente as mulheres, a expectativa de natureza maternal, o controle patriarcal dos corpos, o uso do direito penal para a vigilância da reprodução social e biológica. Não é exagero dizer: as meninas e mulheres morrem, têm medo, se arriscam ao fazerem aborto em situações ilegais e inseguras. Uma em cada cinco mulheres, aos 40 anos, já fez pelo menos um aborto (Diniz, Medeiros, 2010) - iremos mesmo mandar todas elas para a prisão? Quantas famílias seriam afastadas da principal cuidadora, a mulher? E por quê? Porque se acredita falsamente que há um destino natural na vida desde o útero.

3. Qual papel o Direito pode desempenhar para melhoria da desigualdade de gênero no país? 0 espaço jurídico tem se caracterizado, 
em sua opinião, mais pela opressão das mulheres ou pela promoção de seus direitos?

Não há espaços revolucionários ou conservadores como absolutos. Até mesmo nas igrejas - instituições tradicionalmente resistentes à questão feminista - há forças e resistências. Na Igreja Católica, há o grupo das Católicas pelo Direito de Decidir, um exemplo simples de como as organizações não são blocos monolíticos e consensuais ${ }^{3}$. O dissenso é importante e permanente. É assim que entendo o campo do direito - é um campo em disputa, como diria Pierre Bourdieu sobre os campos acadêmicos (Bourdieu, 2002). A particularidade do direito é seu poder de intervenção social: vivemos em uma sociedade mediada pelas leis e pelas cortes (e, extensamente, pelo poder policial). Por essa configuração política do espaço social, o direito se torna um campo potente para a transformação social ou para o conservadorismo.

É assim que há de tudo um pouco nas instâncias formais jurídicas - há juízes pela democracia e magistrados católicos. Não digo como sobreposições privadas ou individuais entre ofícios e crenças, mas como coletivos políticos que se lançam ao espaço social reclamando legitimidade. Não Ihes parece uma incongruência um juiz de Estado laico e democrático reclamar o direito de se apresentar para julgamento como católico? Isso não significa defender a vigilância à ética privada; ao contrário. Significa o reconhecimento de que o espaço social e as instituições básicas do Estado devem ser espaços livres de sobreposições morais que ameacem a democracia. É assim que, repito, o direito é um campo em disputa.

Mas, se há essas ambiguidades no campo do direito, importantes decisões para as mulheres, como o aborto em caso de anencefalia no feto, foram conquistadas pelas cortes, em particular pelo Supremo Tribunal Federal no Brasil. E essa é uma história que parte da beira do leito para as cortes locais: são mulheres diante do diagnóstico de uma anencefalia no feto, isto é, da inviabilidade da vida extrauterina que reclamavam um novo direito (Diniz, 2014). Ser protegida pela legalidade do Estado é uma forma de reconhecimento importante: a dor do luto de uma mulher não é mais objeto de criminalização.

\footnotetext{
${ }^{3}$ Católicas pelo Direito de Decidir é uma organização não-governamental criada em 1993 que conta com grupos atuantes na América Latina, na Europa e nos estados Unidos. Mais informações em: http://catolicas.org.br/.
} 
4. Tratando especificamente do aborto, que é um dos seus objetos de estudo, como foi a experiência de pesquisa sobre as gestações de fetos anencefálicos e de exposição dessa realidade ao sistema judicial brasileiro?

A pergunta me permite explicar um pouco do método com que trabalhamos para o chamado litígio estratégico, seja no grupo que coordeno na Faculdade de Direito da Universidade de Brasília, "Feminismo, Direitos e Políticas", ou na Anis - Instituto de Bioética, organização não-governamental onde sou voluntária ${ }^{4}$. Nossas intervenções judiciais baseiam-se em teses igualitaristas fortes, em um marco feminista dos direitos humanos, mas partem do vivido com estatuto de ciência. O que significa isso? Acreditamos, fortemente, que o direito experimenta um giro argumentativo - por um lado, mantém-se fiel à tradição argumentativa filosófica, mas, por outro, o vivido precisa comunicar-se com as teses abstratas. É nesse giro que a pesquisa empírica ganha força.

Aqui está a fortaleza e a dificuldade histórica de qualquer protagonismo em um campo. Para iniciarmos a ação de anencefalia, atravessamos um longo período de pesquisa empírica em serviços de saúde, de revisão da literatura médica, de conversa com experts em ciência. A tese jurídica é parte do vivido - por isso, não falamos em aborto na ação de anencefalia, mas em antecipação terapêutica do parto, pois assim (ou perto disso) era como as mulheres descreviam a decisão por interromper uma gestação em caso de anencefalia no feto. Aborto é uma categoria forte para os regimes policiais e médicos, e há nela uma intensa carga moral. As mulheres para sobreviver a essa ordem do vivido, que as julga ou como criminosas ou como pecadoras, descreviam a necessidade do procedimento médico de outra maneira.

A ação de anencefalia é resultado de como entendemos esse giro empírico no direito: não é qualquer dado de pesquisa que vale, não é qualquer narrativa ou número de estatística que pode ser utilizado na argumentação. Quando falo no plural aqui, por favor, não me tomem pela tradição régia, mas é porque somos um coletivo de mulheres. E aqui está o desafio histórico do que descrevo como método de pesquisa que antecede nossos litígios estratégicos: acreditamos na ciência como instrumento de poder e saber, mas

\footnotetext{
${ }^{4}$ A Anis - Instituto de Bioética é uma organização feminista não-governamental e sem fins lucrativos, com a missão de promover a cidadania, a igualdade e os direitos humanos para mulheres e outras minorias. Mais informações em: http://anis.org.br/.
} 
também como uma linguagem confiável para a argumentação. Por isso, somos todas pesquisadoras, mesmo as com formação jurídica ortodoxa na equipe. No meu caso, como vocês sabem, sou uma estrangeira ao campo do direito. Ou melhor, uma forasteira bem recebida. E, se posso adicionar algo a esse desafio histórico, é o fato de serem mulheres muito jovens as que darão sentidos a essa nova forma de fazer o direito. Sou a decana do grupo.

5. Um ano depois da decisão do Supremo Tribunal Federal na Ação de Descumprimento de Preceito Fundamental n. 54, noticiou-se que as gestantes de fetos anencefálicos não conseguiam obter a interrupção da gravidez sem embaraços no sistema público de saúde. Você saberia dizer se a efetivação da decisão tomada pelo STF ainda enfrenta dificuldades? De todo modo, quais foram, em sua opinião, os motivos que levaram à demora na implementação do julgamento?

Houve uma conquista importantíssima na ação de anencefalia - o Supremo Tribunal Federal ter reconhecido a não adequação do Código Penal para os casos da gravidez de feto anencefálico. A vitória só foi possível - e estou segura do que digo - porque o ministro Luis Roberto Barroso patrocinou a ação (na época era advogado). Todo o percurso que the contei antes sobre método e preparação só fez sentido, pois o advogado soube transformar a boa ideia, os bons dados, a boa tese em uma argumentação jurídica sólida. O caso foi, para todas nós, um imenso aprendizado sobre como transformar uma boa ideia num caso de sucesso.

A sua pergunta traz um terceiro momento de um litígio estratégico de sucesso. Sim, e depois da vitória da ação? A melhor resposta é lembrar do ocorrido na Colômbia. Em 2006, a Corte Constitucional descriminalizou o aborto em algumas situações, pois o país possuía uma das legislações mais restritivas do mundo (o aborto era proibido inclusive em caso de risco de vida para a mulher). 0 grupo que postulou a ação foi diferente do grupo que transformou o reconhecimento do direito em políticas sociais. Esse é um bom exemplo de como a sociedade civil deve ser mover para efetivar os direitos - o tema de sua pergunta. 
Nós não participamos diretamente do processo de efetivação da decisão do STF no caso da anencefalia, mas até onde sabemos a garantia do acesso aos serviços vem sendo lenta no Brasil - mas não só neste caso específico, mas para todos os permissivos legais de aborto. O país vem enfrentando, nos últimos anos, um retrocesso moral importante esperávamos encontrar mais de 60 serviços de referência para aborto legal em funcionamento no país, mas em pesquisa censitária recente encontramos em torno de 30 apenas (Madeiro, Diniz, 2016). Ou seja, essa dificuldade não é exclusiva da anencefalia, acredito, mas de um conservadorismo que vivenciamos na sociedade brasileira.

\section{Atualmente, você tem pesquisado sobre a epidemia de zika e, em} especial, sobre a situação das gestantes diante das muitas incertezas que uma gravidez passou a representar no país. 0 tema, porém, parece ter perdido espaço nas manchetes de jornal e no debate público de maneira geral. Como você vê esse quadro? Estamos esperando o próximo verão para lidar com o problema? E qual é o tamanho do problema?

Você está absolutamente certa: no momento desta entrevista, julho de 2016, estamos a um mês das Olimpíadas e Paralimpíadas no Brasil e o tema da epidemia do vírus zika é um silêncio. Falamos intensamente das consequências do vírus zika nas mulheres grávidas e da transmissão vertical do vírus aos fetos, causando a síndrome congênita do zika, mas isso, se posso datar, foi até fevereiro deste ano. Desde então, esquecemos epidemia, mulheres e recém-nascidos.

O tamanho do problema pode ser descrito em termos de magnitude de mulheres e crianças afetadas, mas também de densidade ética. São mais de oito mil mulheres com seus recém-nascidos notificados para a síndrome congênita do zika. Repito: milhares de mulheres; e esclareço: não falo microcefalia, mas síndrome congênita do zika. Essa é uma diferença importante para a nossa conversa. Por simplificações ou falta de informação, as pessoas falam em microcefalia, mas esta é uma confusão básica em medicina de tomar um sintoma por uma doença. O vírus zika na gravidez pode causar uma síndrome congênita no feto. Há vários sinais e sintomas, desde problemas visuais, auditivos, motores e cognitivos até a microcefalia. Mas já há casos relatados na ciência de recémnascidos afetados sem o sintoma da microcefalia, ou seja, com perímetro cefálico regular. 
Em termos de magnitude é isso: milhares de mulheres, quase todas de municípios remotos do Nordeste, cidades pobres, mulheres distantes de nossos marcos hegemônicos de reconhecimento para a vida digna. Essas mulheres nordestinas eram já esquecidas e anônimas, a epidemia só as distanciou ainda mais de nós. Aqui começo a passar da magnitude para a densidade ética da epidemia. Lançarei em agosto o livro "Zika: do sertão nordestino à ameaça global", pela editora Civilização Brasileira, em que conto a história da epidemia pelos dois capítulos principais: a identificação do novo vírus circulando no país, e a descoberta de uma nova doença - a síndrome congênita do zika.

Além do livro, fiz um filme documentário, "Zika", que conta a história de cinco mulheres e médicas do Cariri, na Paraíba (Diniz, 2016b). Campina Grande é um dos epicentros da epidemia do vírus zika no país - foi ali que conheci Amanda, Marina, Alessandra, Ana Angélica e Géssica. Cada uma delas viveu de maneira diferente a tragédia de uma epidemia que poderia ser evitada no país se não convivêssemos há 40 anos com o mosquito vetor, Aedes aegypti. Amanda é a mulher que vive o instante do diagnóstico do filho de cabeça pequena e com múltiplas calcificações; Marina, a mulher católica que se vê em risco de vida e escolheu o aborto; Alessandra, a mãe cuidadora que fez da dependência do filho o sentido da existência; Ana Angélica, a sertaneja que fala pela linguagem dos direitos e se move pelos interiores para estimular precocemente a filha afetada pelo vírus zika; Géssica, a primeira mulher a doar líquido amniótico do feto com sintomas da síndrome congênita do zika para a ciência.

Foi de Géssica e Conceição, duas vizinhas que não se conheciam em Juazeirinho, que a ciência pela primeira vez isolou o vírus no líquido amniótico - era uma prova de que o zika atravessava a parede placentária. O filho de Géssica não sobreviveu ao parto.

7. Conforme noticiado, você participa de um grupo de estudiosos, de diferentes instituições, que pretende ingressar com uma ação no STF questionando a atuação do Estado brasileiro diante da epidemia de zika. É possível adiantar detalhes do que será pedido na ação e quais serão os seus principais fundamentos?

Sim, é um prazer, pois não há segredo e conversar sobre a ação é uma forma de qualificala. Ela será apresentada pela Associação Nacional dos Defensores Públicos (ANADEP), e 
uma das advogadas é Sinara Gumieri, pesquisadora da Anis ${ }^{5}$. Seis meses depois de a crise de saúde pública do vírus zika se tornar um tema global, muitas dúvidas científicas permanecem. Mas, se não temos todas as respostas médicas que gostaríamos, sabemos como cuidar de direitos. As mulheres e famílias afetadas pela epidemia vivem, sob o marco da desigualdade, um quadro de direitos violados anterior ao vírus zika e agravado por ele: as falhas no saneamento básico, no acesso regular à água e no controle vetorial fizeram do mosquito mais um membro das casas, com os quais famílias nordestinas são obrigadas a conviver há gerações. Apesar da negligência, o Estado brasileiro não tem se movido adequadamente para responder à epidemia.

A proposta de ação ao Supremo Tribunal Federal tem como marco a dignidade das mulheres. Se o mosquito não diferencia cidadãos brasileiros e turistas olímpicos entre alvos potenciais, são mulheres em idade reprodutiva, nordestinas e pobres, aquelas cujos projetos de vida são desestabilizados na epidemia. Suas decisões reprodutivas são colocadas em questão, já que viver uma gravidez em tempos de epidemia e incertezas científicas as sujeita a um sofrimento psíquico intenso, além de outras ameaças à saúde que ainda precisam ser mais bem investigadas. Aquelas que podem seguir com a gestação frequentemente enfrentam a perspectiva de cuidados permanentes a crianças cujas necessidades singulares de saúde ainda estão sendo descobertas: elas não se tornam apenas mães, mas também cientistas da casa, atentas a cada novo detalhe do desenvolvimento de seus bebês. A vida dedicada a cuidados diários - que não cabe em uma descrição liberal ingênua de escolha em nosso marco familiar patriarcal - exige que se afastem de atividades que lhes geravam renda, para garantir que estarão com seus bebês no transporte a caminho de sessões semanais de estimulação precoce, em consultas médicas, em filas do INSS.

O que a ação ao STF pedirá é que o Estado brasileiro leve a sério os direitos das mulheres e das crianças afetadas pela síndrome congênita do zika: direito ao planejamento familiar; à saúde; à proteção social à maternidade, à infância e a pessoas com deficiência; e à assistência social "a quem dela necessitar", em termos constitucionais. Todas as mulheres em idade reprodutiva devem ter acesso a informações de qualidade e atualizadas sobre o vírus zika e suas formas de transmissão - inclusive a sexual -, sobre os riscos da infecção na gravidez e também sobre as incertezas da transmissão vertical e da síndrome congênita. Devem ter acesso a "todos os métodos e

${ }^{5}$ A ação foi ajuizada em 24.08.2016. Trata-se de ação direta de inconstitucionalidade (ADI), processada no STF sob o n. 5581 e distribuída para relatoria da Ministra Cármen Lúcia. 
técnicas de concepção e contracepção cientificamente aceitos (...), garantida a liberdade de opção" - e aqui cito a Lei de Planejamento Familiar -, incluindo acesso a métodos contraceptivos reversíveis de longa duração para as que não quiserem engravidar, e a repelentes como prevenção ao vírus zika para as que quiserem. As mulheres grávidas e infectadas pelo zika que estiverem em sofrimento psíquico pelas incertezas dos que as espera nos exames pré-natais devem ter o direito de escolher seguir ou não com a gestação, sendo encaminhadas a serviços de aborto legal se o cuidado de sua saúde assim exigir. O estado de necessidade gerado pela epidemia e pela ameaça à saúde - física, mental e social, no conceito da Organização Mundial de Saúde - das mulheres tem que afastar os efeitos penais da criminalização do aborto (como, aliás, já o faz no caso do estupro, em que não se fala em qualquer condição ou diagnóstico fetal, mas na saúde e dignidade da mulher). Os bebês com deficiências associadas ao zika têm que ter acesso a serviços de saúde próximos de suas residências, e, se isso não for possível, o transporte sanitário tem que ser garantido. Esses bebês e suas famílias têm que ter acesso universal ao benefício de prestação continuada, com reconhecimento da inconstitucionalidade do critério de renda de um quarto de salário-mínimo por pessoa da família, que hoje o torna inacessivel a quem dele necessita para cuidados básicos. A quantidade de pedidos é reflexo da negligência do estado brasileiro. Mas não temos dúvida: isso é o mínimo necessário para que direitos das mulheres e de pessoas com deficiência sejam levados a sério.

\section{Referências Bibliográficas}

Beauvoir, Simone de. 0 segundo sexo (1949). Trad. de Sergio Millet. 2. ed. Rio de Janeiro: Nova Fronteira, 2009.

Bourdieu, Pierre. Pierre Bourdieu entrevistado por Maria Andréa Loyola. Rio de Janeiro: EdUERJ, 2002.

Butler, Judith. Problemas de gênero: feminismo e subversão da identidade (1990). Trad. de Renato Aguiar. Rio de Janeiro: Civilização Brasileira, 2003.

Diniz, Debora. A arquitetura de uma ação em três atos. Revista Direito.UnB. Brasília. V. 1, n. 2. Julho-Dezembro, 2014.

Etnografia e políticas da vida - a introdução. In: Fassin, Didier. Didier Fassin entrevistado por Debora Diniz. Rio de Janeiro: EdUERJ, 2015a. p. 7-30.

Feminismo: modos de ver e mover-se. In: Gomes, Patrícia; Diniz, Debora; Santos, Maria Helena; Diogo, Rosália. O que é feminismo? Lisboa: Escolar Editora, 2015b. p. 47-60. 
Quinquilharia - 0 lugar de fala (vídeo). 2016. Disponível em: <https://www.youtube.com/watch?v=baMQxkv-duc\&list=PLf-Oz5dUh_ni-Fk3zkalLPc0xC1sAxyX\&index=23>. Acesso em 31 Jul. 2016.

Zika. Documentário. Disponível em: <https://www.youtube.com/watch?v=j9tqt0jaoG0>. Acesso em: 16 Abr. 2016.

Diniz, Debora; Medeiros, Marcelo. Aborto no Brasil: uma pesquisa domiciliar com técnica de urna. Ciênc. saúde coletiva, Rio de Janeiro, v. 15, supl. 1, p. 959-966, Junho 2010. Disponível em: <http://www.scielo.br/scielo.php?script=sci_arttext\&pid=S141381232010000700002\&lng=en\&nrm=iso>. Acesso em: 31 Jul. 2016.

Madeiro, Alberto Pereira; Diniz, Debora. Serviços de aborto legal no Brasil - um estudo nacional. Ciênc. saúde coletiva, Rio de Janeiro, v. 21, n. 2, p. 563-572, Fev. 2016. Disponível em: <http://www.scielo.br/scielo.php?script=sci_arttext\&pid=S141381232016000200563\&lng=en\&nrm=iso>. Acesso em: 02 Ago. 2016. 